\title{
Towards the "Pressure and Materials Gap": Hydrogenation of Acrolein Using Silver Catalysts
}

\author{
By M. Bron ${ }^{1}$, E. Kondratenko ${ }^{2}$, A. Trunschke ${ }^{2}$, and P. Claus ${ }^{1, *}$
}

${ }^{1}$ Darmstadt University of Technology, Dep. Chemistry, Chemical Technology II, Petersenstr. 20, D-64287 Darmstadt, Germany

2 Institute for Applied Chemistry Berlin-Adlershof, Richard-Willstätter-Str. 12, D-12489 Berlin, Germany

Dedicated to Prof. Dr. Klaus Scherzer on the occasion of his $70^{\text {th }}$ birthday

(Received January 16, 2004; accepted February 5, 2004)

\section{Hydrogenation / Silver Catalyst / Silver Nanoparticles / Acrolein / Selectivity / Pressure Effect / Adsorption Calorimetry / TAP Reactor / IR / Structure-Sensitivity}

The hydrogenation of acrolein has been studied over various $\mathrm{Ag} / \mathrm{SiO}_{2}$ catalysts in a pressure range from $50 \mathrm{mbar}$ to 20 bar. Increasing partial pressures of acrolein and/or hydrogen lead to increasing selectivities of allyl alcohol. The selectivity towards allyl alcohol also depends on the structural features of the $\mathrm{Ag} / \mathrm{SiO}_{2}$ catalyst. Larger particles seem to favour the production of propanal. This observation is discussed in view of the different plane-to-edge-ratio of the different catalysts. The interaction of hydrogen with silver samples has been studied with TAP at very low pressures as well as with calorimetry at ambient pressures. Both methods indicate, that also the hydrogen adsorption is structure-sensitive. No interaction of hydrogen with electrolytic silver or the support material alone was observed. IR spectroscopy has been used to elucidate the interaction of acrolein with $\mathrm{Ag} / \mathrm{SiO}_{2}$ catalysts. A strong interaction with the support material was found, hindering the observation of probable silver-acrolein interaction.

\section{Introduction}

Silver, usually known as oxidation catalyst used in ethylene epoxidation, exhibits interesting properties when used in hydrogenation reactions. For instance, in the gas phase hydrogenation of crotonaldehyde (an $\alpha, \beta$-unsaturated

* Corresponding author. E-mail: claus@ct.chemie.tu-darmstadt.de 
aldehyde), selectivities to the corresponding unsaturated alcohol (crotyl alcohol, product of the $\mathrm{C}=\mathrm{O}$ group hydrogenation) of around $60 \%$ can be obtained [1]. More commonly used metals like $\mathrm{Pd}, \mathrm{Pt}, \mathrm{Ni}$ or $\mathrm{Ru}$, supported on non-reducible oxides such as $\mathrm{SiO}_{2}$ or $\mathrm{Al}_{2} \mathrm{O}_{3}$, mainly produce the saturated aldehyde which is the product of the $\mathrm{C}=\mathrm{C}$ bond hydrogenation. Both reaction products can be hydrogenated in consecutive reactions to the saturated alcohol butanol. To understand the unusual hydrogenation properties of silver catalysts and to correlate their catalytic behaviour with structural features, application of powerful methods of catalyst characterization is necessary. Recently, we reported detailed characterisation of $\mathrm{Ag} / \mathrm{SiO}_{2}$ and $\mathrm{Ag} / \mathrm{TiO}_{2}$ catalysts by conventional (CTEM) and high-resolution transmission electron microscopy (HRTEM), assisted by selected area electron diffraction, with the aim of studying the influence of the silver particle size on activity and selectivity of the gas-phase hydrogenation of crotonaldehyde [1]. Structural details of $\mathrm{Ag} / \mathrm{TiO}_{2}$ catalysts, after different pretreatment procedures like low- and high-temperature reduction were elucidated in relation to their influence on activity and selectivity in the gas-phase hydrogenation of acrolein, which is the $\alpha, \beta$-unsaturated aldehyde most difficult to hydrogenate selectively at the carbonyl group. Spectroscopic techniques such as XPS, UPS and ISS were used to examine the oxidation state of silver supported as small nanosized particles $(<3 \mathrm{~nm})$ on titania as well as possible changes of their electronic properties and surface coverage phenomena connected with metal $(\mathrm{Ag})$-support $\left(\mathrm{TiO}_{2}, \mathrm{TiO}_{x}\right)$ interactions [2]. Additionally, in-situ ESR spectroscopy was used to prove whether the dispersion is high enough to yield Ag surface clusters showing the quantum size effect.

However, the reason for the intrinsic selectivity to unsaturated alcohols, i.e. the role of silver when acting as hydrogenation catalyst is not well understood at the moment. The reason for this is twofold: Only little is known about the interaction of hydrogen with silver nanoparticles, i.e. the question, whether hydrogen is dissociated or not, and the energetics of this process. Additionally, the interaction of unsaturated aldehydes with silver has, in opposite to other metals like $\mathrm{Pt}$, only been the subject of few investigations.

For example, Itoh and co-workers have studied the acrolein adsorption at evaporated silver films at low pressures and temperatures [3]. They have found an exposure (i.e., coverage) dependent adsorption geometry. Four types of structures of acrolein have been found at the silver surface at $90 \mathrm{~K}$, with form successively after increasing exposure to acrolein. For the first two structures, a direct interaction of acrolein with silver has been proposed, whereas the structures formed after higher exposure are described as multilayers. In all cases, the molecular plane is more or less parallel to the surface. Electropositive sites like kinks and edges favour the coordination of the $\mathrm{C}=\mathrm{O}$ group. Madix et al. $[4,5]$ showed that stabilization of the $\mathrm{C}=\mathrm{C}$ bond in the vicinity of the surface did not lead to hydrogenation over $\operatorname{Ag}(110)$. 
Furthermore, it is interesting to note that from a combined TPD and HREELS study of the oxidation of $\pi$-allyl $\left(\eta^{3}-\mathrm{C}_{3} \mathrm{H}_{5}\right)$, prepared on atomic oxygen- and hydroxyl covered $\operatorname{Ag}(110)$ surface, adsorption enthalpies for acrolein (reactant of our study), the half-hydrogenated surface intermediate of acrolein according to a Horiuti-Polanyi mechanism, and allyl alcohol (product) are available $\left(-59,-239\right.$ and $-71 \mathrm{~kJ} \mathrm{~mol}^{-1}$, respectively) [6] indicating a strong adsorption. Hydrogen, on the other hand, is known to interact only very weakly with flat silver planes (initial heat of adsorption $\approx 15 \mathrm{~kJ} \mathrm{~mol}^{-1}$ on $\operatorname{Ag}(111)$ [7]). Demuth et al. have investigated the adsorption of hydrogen at polycrystalline silver and $\mathrm{Ag}(111)$ with EELS and found molecularly adsorbed hydrogen at very low temperatures (below $20 \mathrm{~K}$ ) [8,9]. Zhukov et al. [10] have studied the desorption of $\mathrm{H}_{2}$ from silver single crystal surfaces. They used atomic hydrogen to precover the surface because of the very high activation barrier for molecular adsorption, as also pointed out by Eichler et al. in the case of $\mathrm{Ag}(100)$ [11]. Differences between different single crystal surfaces and a desorption energy of $7 \mathrm{kcal} / \mathrm{mol}$ in the case of $\mathrm{Ag}(111)$ as well as reconstructed silver surfaces have been found [10]. On the other hand, Ehwald et al. [12] have investigated the isotope kinetics of the interaction of ethylene with a supported silver catalyst. They have found a relatively fast dissociation of hydrogen but the amount of hydrogen adsorbed at highly dispersed silver is very low compared to the amount of oxygen, as pointed out by Vannice and co-workers some time ago $[13,14]$.

A look at the differences between silver single crystals and nanoparticles concerning the adsorption of hydrogen leads to a general problem in catalysis: the question whether the results from surface science studies in UHV using well defined, relatively easy to characterise model systems (i.e. single crystals) on one side, can be transferred to "real" catalysis on the other side, i.e., high pressure and highly disperse, complex and difficult to characterise (at least under reaction conditions) catalysts. This question is often referred to as "pressure gap" and "materials gap". The aim of our studies is to contribute to this question and to try to bridge these gaps using the hydrogenation of acrolein over silver catalysts as model reaction within the priority program 1091 of the DFG (German research foundation). Therefore, we have investigated the acrolein hydrogenation at various silver samples, namely, single crystals, sputtered silver samples and silica supported silver catalysts with high silver dispersion. This paper will focus on the latter, which have been investigated in the pressure range from 5 to $20 \mathrm{MPa}$, data in the range down to $50 \mathrm{mbar}$ are also available. However, to get a detailed understanding of the processes occurring during acrolein hydrogenation over silver, it is also necessary to investigate the interaction of each reactant (hydrogen and acrolein) with the catalyst. Therefore, TAP (transient analysis of products) in the low pressure range (Knudsen regime) as well as gas adsorption calorimetric measurements at ambient pressures have been performed to investigate the interaction of hydrogen with various catalyst samples. The adsorption of acrolein at silica 
supported silver catalysts has been studied with IR spectroscopy. More sophisticated measurements using in situ-XAS under reaction conditions (up to $10 \mathrm{mbar}$ ) have also been performed, however, since most of these measurements have been done at single crystals, they will be presented in a different paper [15].

\section{Experimental}

\subsection{Catalyst preparation}

Catalysts containing nominal 9\% Ag supported onto silica gel have been prepared via incipient wetness technique (IW), via precipitation (P) and via solgel-technique (SG).

For the IW-catalyst, $20 \mathrm{~g}$ of silica gel (Alfa, "large pore", $d_{\mathrm{p}}=15 \mathrm{~nm}$ ), $d_{\text {particle }}=0.2-0.5 \mathrm{~mm}$, have been dried under vacuum in an oven at $110^{\circ} \mathrm{C}$ for $3 \mathrm{~h}$. After cooling down, $42 \mathrm{ml}$ of an aqueous solution containing $3.63 \mathrm{~g}$ of silver lactate (Fluka, "for histology") have been added to the dried silica gel. The catalyst has then been dried in a desiccator.

Two catalysts have been prepared via precipitation. In both cases, $20 \mathrm{~g}$ of silica gel have been suspended in $80 \mathrm{ml}$ of deionized water. A solution of $3.2 \mathrm{~g}$ $\mathrm{AgNO}_{3}$ (Fluka, "reinst") in $50 \mathrm{ml} \mathrm{H}_{2} \mathrm{O}$ and either a solution of $1.16 \mathrm{~g} \mathrm{NaOH}$ (Merck, p.A.) in $50 \mathrm{ml} \mathrm{H}_{2} \mathrm{O}$ or $2.35 \mathrm{~g} \mathrm{Na}_{2} \mathrm{CO}_{3}$ (Merck, "suprapur") in $50 \mathrm{ml}$ $\mathrm{H}_{2} \mathrm{O}$ have been added to this suspension under vigorous stirring within one minute. Afterwards, the suspension has been stirred for $3 \mathrm{~h}$ followed by filtering and thoroughly washing the filtrate. Finally, the catalyst precursors have been dried in a desiccator.

The sol-gel catalyst $\left(\mathrm{Ag} / \mathrm{SiO}_{2}-\mathrm{SG}\right)$ has been prepared as described in [16].

The catalysts prepared via precipitaion have been calcined in flowing air at $250^{\circ} \mathrm{C}$ for $2 \mathrm{~h}$ and reduced in flowing hydrogen at $325^{\circ} \mathrm{C}$ for $2 \mathrm{~h}$ and are labelled in the following as $9 \mathrm{Ag} / \mathrm{SiO}_{2}-\mathrm{P}(\mathrm{NaOH})$ and $9 \mathrm{Ag} / \mathrm{SiO}_{2}-\mathrm{P}\left(\mathrm{Na}_{2} \mathrm{CO}_{3}\right)$. The SG-catalyst has been calcined at $400{ }^{\circ} \mathrm{C}$ for $2 \mathrm{~h}$ and then reduced at $325^{\circ} \mathrm{C}$ for $2 \mathrm{~h}$ and the IW-catalyst has been reduced only $\left(2 \mathrm{~h}, 325^{\circ} \mathrm{C}\right)$. It will be referred to in the following as $9 \mathrm{Ag} / \mathrm{SiO}_{2}-\mathrm{IW}$. Before each catalytic experiment, each catalyst has been reduced again in situ (i.e., in the catalytic reactor) at $325^{\circ} \mathrm{C}$ for $0.5 \mathrm{~h}$.

The real metal content of the reduced catalysts has been determined using ICP-OES. The results are summarised in Table 1.

\subsection{Gas-phase hydrogenation of acrolein}

The catalytic tests have been performed using a fixed-bed flow micro-reaction system, as described in detail previously [17]. The system is equipped with a unit for continuous gas feed, a liquid feed unit with an evaporator, a tubular reactor and an online GC analytic. Typically, $200 \mathrm{mg}$ of catalyst have 


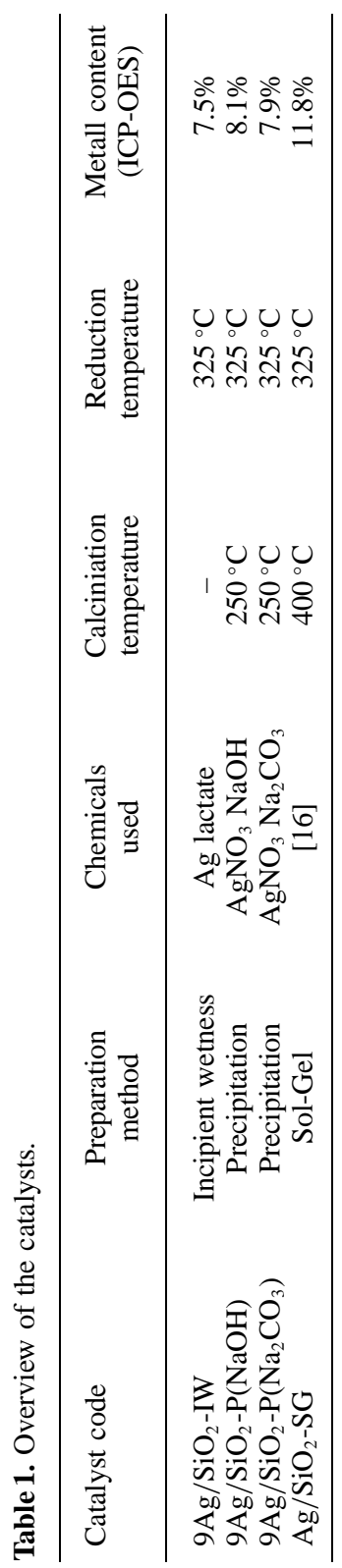

been used, depending of the activity of the catalysts. Hydrogen (5.0, MesserGriesheim) and acrolein (97\%, stabilised, Acros, purity checked with GC) have been used as reactants. Argon (5.0, Messer-Griesheim) has been used as balance gas. Experiments have been performed in a pressure range ranging 
from 0.5 to $2 \mathrm{MPa}$ (5 to $20 \mathrm{bar}$ ). Data in the region of $50-1000 \mathrm{mbar}$ are also available.

\subsubsection{Calorimetric experiments}

Gas adsorption calorimetry has been performed using a Setaram DSC 111 differential scanning calorimeter equipped with a system allowing the dosage of small amounts of gas into a stream of carrier gas. Typically, $50 \mathrm{mg}$ of catalyst have been filled in a quartz reactor tube and been mounted into the sensor of the calorimeter. After reduction at $325^{\circ} \mathrm{C}$ in flowing hydrogen, the catalyst has been treated at the same temperature in an Ar flow for at least $1 \mathrm{~h}$ in order to desorb hydrogen. Afterwards, the temperature has been changed to $50{ }^{\circ} \mathrm{C}, 150{ }^{\circ} \mathrm{C}$ or $250{ }^{\circ} \mathrm{C}$, and a sequence of pulses of hydrogen has been dosed into the carrier gas Ar. The heat flow during adsorption (and often subsequent desorption) of hydrogen has been monitored via the calorimetric sensor. Additionally, attempts have been made to determine the amount of adsorbed hydrogen via a thermal conductivity detector. However, it turned out that the amount of hydrogen irreversibly adsorbed at the silver catalysts, if there is any, is very low and therefore below the detection accuracy of our detection system. For this reason, only qualitative data can be given at the moment (see results for details).

It has to be mentioned that the carrier gas (Ar 5.0) has been further cleaned with Oxisorb ${ }^{\circledR}$ from Merck in order to avoid any contamination of the catalysts with oxygen.

\subsubsection{Transient measurements in the TAP reactor}

The TAP-2 reactor system, in which all transient experiments were carried out, has been described in detail elsewhere [18]. The catalyst (10-50 mg; $d_{\text {particle }}=250-355 \mu \mathrm{m}$ ) was packed between two layers of quartz of the same particle size in the isothermal zone of a quartz reactor $(6 \mathrm{~mm}$ i.d.). Prior to the experiments, the catalyst was reduced in a $\mathrm{H}_{2}$ flow $(50 \mathrm{ml} / \mathrm{min})$ at $400{ }^{\circ} \mathrm{C}$ for $2 \mathrm{~h}$. After this pre-treatment the reactor was evacuated and $\mathrm{H}_{2} / \mathrm{Ne}(1: 1)$, $\mathrm{D}_{2} / \mathrm{Ne}(1: 1)$ or acrolein/Ne (1:1) mixtures were separately pulsed over the catalyst in the temperature range between 100 and $500{ }^{\circ} \mathrm{C}$ using pulse sizes between $2 \times 10^{14}$ and $4 \times 10^{14}$ molecules/pulse corresponding to the Knudsen diffusion regime. This means that the transient responses are a function of gas-solid interactions and not influenced by collisions between gas-phase molecules. Thus primary heterogeneous reaction steps are under investigation.

For mass spectroscopic identification of the different compounds, the following atomic mass units (AMUs) were used: $132(\mathrm{Xe}), 56$ (acrolein), $20(\mathrm{Ne})$, $18\left(\mathrm{H}_{2} \mathrm{O}\right) ; 4\left(\mathrm{D}_{2}\right), 3(\mathrm{HD}), 2\left(\mathrm{H}_{2}\right)$. For each AMU, pulses were repeated 10 times and averaged to improve signal to noise ratio. The sensitivity factors were determined for acrolein, $\mathrm{H}_{2}$ and $\mathrm{D}_{2}$. For calculation of the $\mathrm{HD}$ yields, it was assumed that its sensitivity is equal to that of $\mathrm{D}_{2}$. 


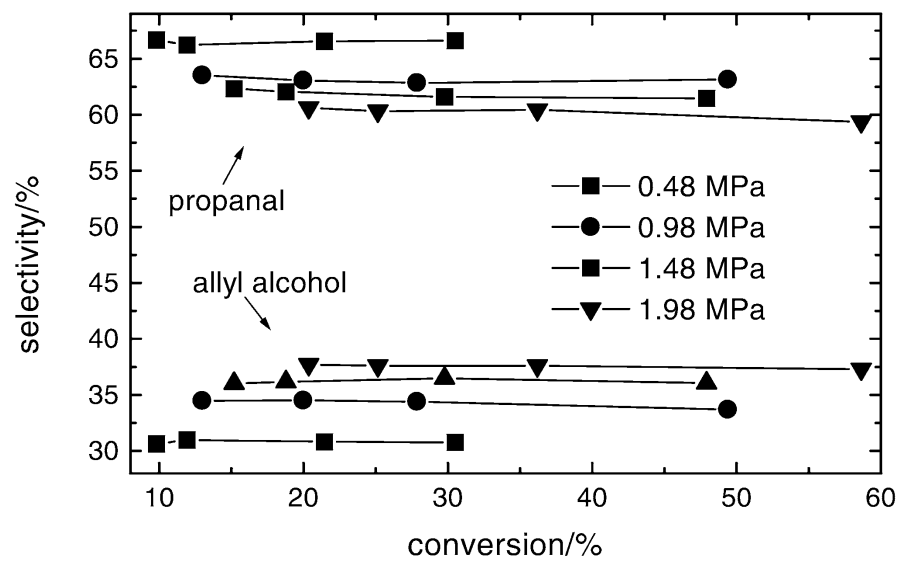

Fig. 1. Dependence of the selectivity towards the main hydrogenation products allyl alcohol and propanal on the degree of acrolein conversion in the gas phase hydrogenation of acrolein over $9 \mathrm{Ag} / \mathrm{SiO}_{2}-\mathrm{P}(\mathrm{NaOH})$. Reaction conditions: $250{ }^{\circ} \mathrm{C}$, varying pressures between 0.48 and $1.98 \mathrm{MPa}$. The conversion has been varied via the ratio catalyst mass/molar feed of acrolein.

\subsubsection{Infrared spectroscopy}

The infrared measurements were performed using an in situ quartz cell with $\mathrm{CaF}_{2}$ windows. The catalyst was pressed in the form of a self-supporting wafer $\left(\sim 10 \mathrm{mg} \mathrm{cm}^{-2}\right)$. Acrolein was adsorbed after reduction in flowing $\mathrm{H}_{2}$ $\left(20 \mathrm{ml} \mathrm{min}^{-1}\right)$ at $250{ }^{\circ} \mathrm{C}$ and evacuation of the wafer at the same temperature. Spectra were recorded at resolution of $2 \mathrm{~cm}^{-1}$ using a Digilab FTS 60-A spectrometer, co-adding 64 scans.

\section{Results}

\subsection{Acrolein hydrogenation}

Fig. 1 shows the selectivity-conversion plot for allyl alcohol and propanal during the gas-phase hydrogenation of acrolein at various pressures using the $9 \mathrm{Ag} / \mathrm{SiO}_{2}-\mathrm{P}(\mathrm{NaOH})$ catalyst. Allyl alcohol and propanal are the main hydrogenation products. The selectivity towards the product of the consecutive reduction, $n$-propanol, has always been found to be far below $5 \%$ up to $50 \%$ degree of acrolein conversion. A higher selectivity (up to 10\%) was found only for the sol-gel-derived catalyst. Selectivity to other by-products was below $2.5 \%$. Form the results presented in Fig. 1, it is clear that the selectivity to allyl alcohol and propanal is nearly independent of the degree of acrolein conversion in the examined range. However, the product distribution depends strongly on the reaction pressure: the higher the total pressure, the higher the 


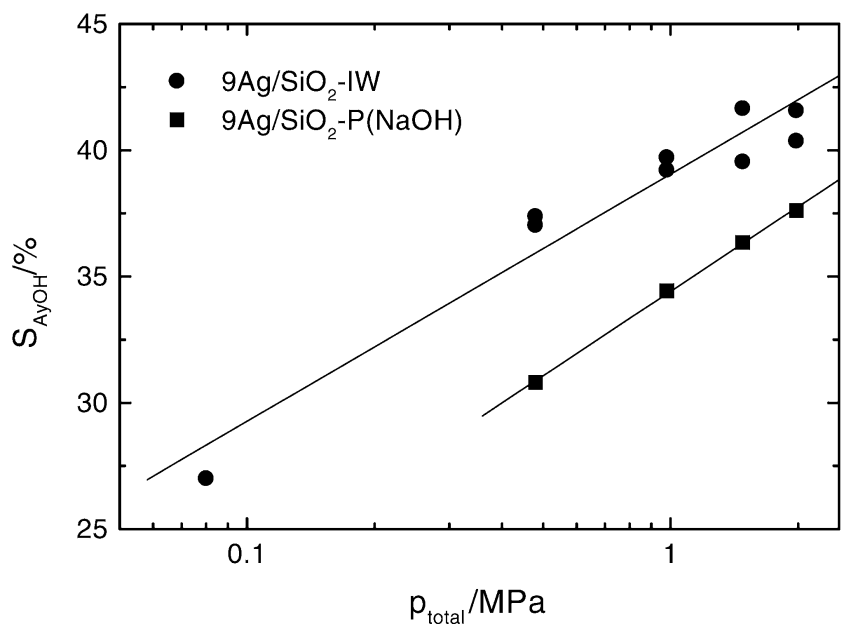

Fig. 2. Dependence of the selectivity towards allyl alcohol on the total pressure in the gas phase hydrogenation of acrolein over two different $\mathrm{Ag} / \mathrm{SiO}_{2}$ catalysts. Conversion for all data points was $c a$. $25 \%$, reaction temperature was $250{ }^{\circ} \mathrm{C}$.

concentration of allyl alcohol and the lower the concentration of propanal. This dependence is displayed explicitly in Fig. 2, where the selectivity towards allyl alcohol in the gas phase hydrogenation of acrolein over two different silver catalysts is shown $v s . \log p$ at constant conversion of $25 \%$ exhibiting a linear dependence. A more detailed investigation of the pressure dependence showed, that partial pressures of hydrogen and acrolein influence the catalytic performance considerably stronger than the total pressure. An increase in the total pressure by adding argon to the reaction mixture without changing the partial pressures of hydrogen and acrolein does not significantly influence the selectivities obtained in the hydrogenation of acrolein. However, the selectivity towards allyl alcohol increases strongly with an increase in either partial pressure of acrolein or hydrogen keeping the total pressure constant (Fig. 3). In Fig. 3(a) and (b), the selectivity to allyl alcohol is displayed as a function of hydrogen and acrolein partial pressures, respectively. Therefore, the observed increase in selectivity to allyl alcohol (Fig. 2) is due to the increased partial pressures of acrolein and hydrogen.

Additionally to the dependence of the selectivity on pressure, a dependence on the preparation method of the catalyst can be seen. The lowest selectivity towards allylic alcohol has been obtained over the catalysts prepared via precipitation, the highest over the IW-catalyst. Even higher selectivities towards allyl alcohol (up to $44 \%$ at $2 \mathrm{MPa}$ ) have been found using the sol-gel-derived catalyst, however, with this catalyst, different from all other catalysts used in this study, a constant deactivation as well as a decrease in selectivity towards allyl alcohol have been observed with time on stream. For instance, a decrease 

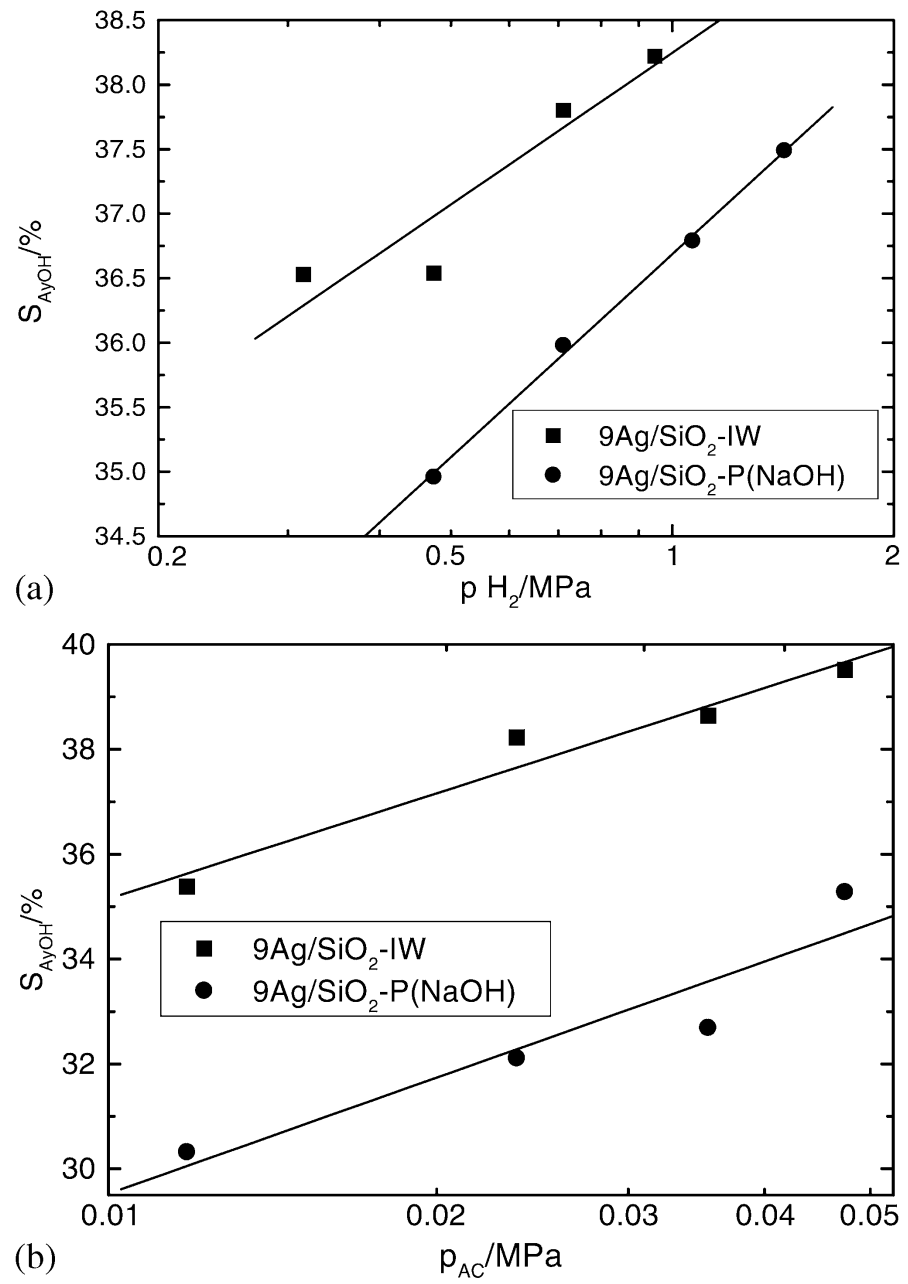

Fig. 3. a) Dependence of the selectivity to allyl alcohol on partial pressure of hydrogen in the gas phase hydrogenation of acrolein over two different $\mathrm{Ag} / \mathrm{SiO}_{2}$ catalysts at $250{ }^{\circ} \mathrm{C}$. b) Dependence of the selectivity to allyl alcohol on partial pressure of acrolein in the gas phase hydrogenation of acrolein over two different $\mathrm{Ag} / \mathrm{SiO}_{2}$ catalysts at $250^{\circ} \mathrm{C}$.

in conversion from $13 \%$ to $3 \%$ as well as a decrease in $S_{\mathrm{AyOH}}$ from $44 \%$ to $36 \%$ have been observed after $12.5 \mathrm{~h}$ time on stream.

To elucidate the influence of the support on the selectivity in the acrolein hydrogenation, silica supported catalysts with different metal content and a support-free silver catalyst have been prepared via a precipitation method. It has been found, that the selectivities to allyl alcohol and propanal do not depend on the amount of support present in the catalyst. Therefore, the pres- 

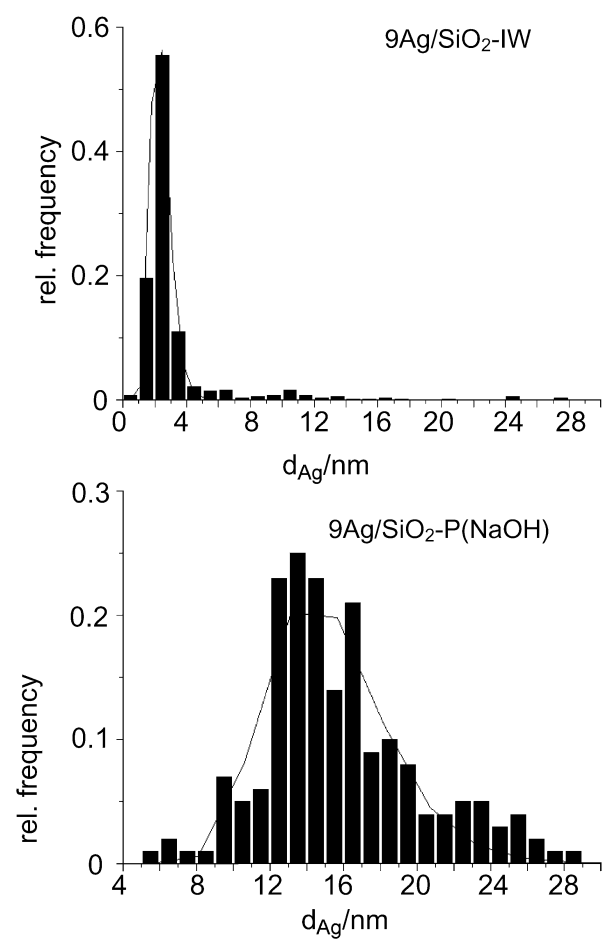

Fig. 4. Particle size distribution for the catalysts $9 \mathrm{Ag} / \mathrm{SiO}_{2}-\mathrm{IW}$ (upper part) and $9 \mathrm{Ag} / \mathrm{SiO}_{2}-$ $\mathrm{P}(\mathrm{NaOH})$ (lower part) as obtained from TEM measurements. Same catalysts as for Figs. 2, 3 and 5 as well as for the TAP measurements.

ence of silica support does not seem to influence the selectivities. On the other hand, IR spectroscopic experiments on the interaction of acrolein (see below) as well as very recent results on $\mathrm{H}_{2}-\mathrm{Ag} / \mathrm{SiO}_{2}$-interaction [19] indicate, that both molecules are interacting not only with the Ag particles, but also with the support.

\subsection{Catalyst characterisation}

The structural analysis of the catalysts has been carried out using TEM (JEM 100C) and XPS or X-ray induced Auger electron spectroscopy, respectively. The latter methods indicated, that silver is present in its metallic form in all catalysts. Details on the XPS investigations will be presented elsewhere [15].

The particle size distributions of various catalysts have been determined with TEM. For the IW- and the P-catalyst, these distributions are presented in Fig. 4. A narrow size distribution with small particles can be seen for the IW catalyst, whereas a broader distribution and larger particles are found for the 


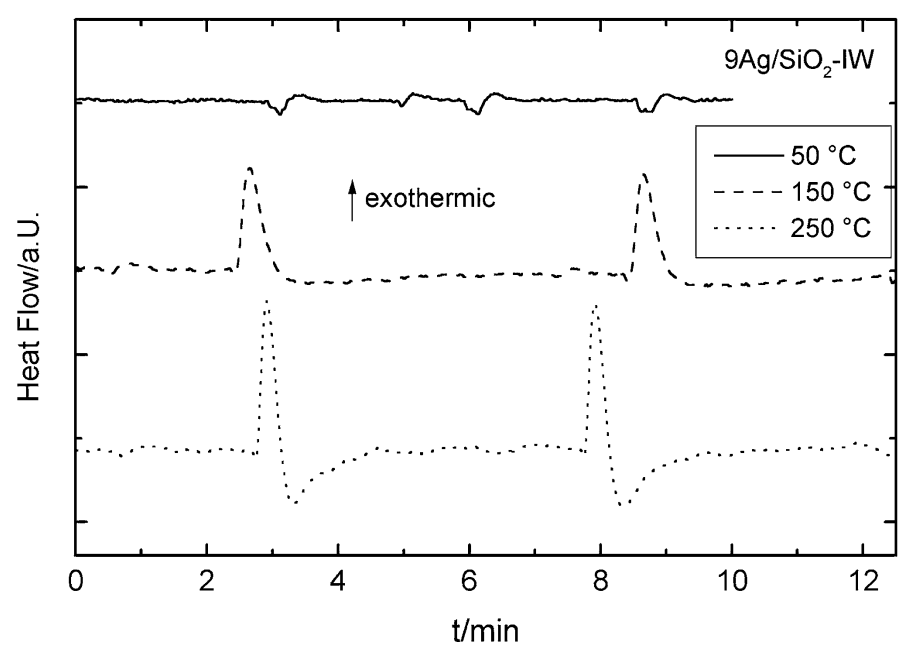

Fig. 5. Temperature dependence of the heat flow signals caused by hydrogen adsorption at $9 \mathrm{Ag} / \mathrm{SiO}_{2}$-IW. $17.6 \mu \mathrm{l}$ of hydrogen (diluted with $\mathrm{Ar}$ ) have been dosed per pulse. $m_{\text {cat }}=100 \mathrm{mg}$.

P-catalyst. For the precipitation catalysts with higher metal loadings, it was difficult to determine the particle size distribution, since it has been found that small particles of several $\mathrm{nm}$ coexist with large agglomerates in the $100 \mathrm{~nm}$ range.

\subsection{Calorimetric measurements}

In order to gain information about the interaction of hydrogen with the silver catalysts, adsorption calorimetry studies have been performed with a pulse adsorption setup, as described in the experimental section. Fig. 5 shows the temperature dependence of the calorimetric signal, when a silver catalyst is exposed to pulses of hydrogen. In these experiments, exothermic signals are attributed to the adsorption of hydrogen, whereas the endothermic peaks are due to the subsequent desorption of previously adsorbed hydrogen.

It can be seen, that only very weak signals are obtained at $50{ }^{\circ} \mathrm{C}$, which are hardly distinguishable from the signals obtained in reference experiments using empty reactors or reactors filled with support material only.

At higher temperatures, exothermic signals followed by endothermic ones can be observed. These endothermic signals are only very weak at $150{ }^{\circ} \mathrm{C}$, but more pronounced at $250{ }^{\circ} \mathrm{C}$. However, a more detailed analysis reveals, that in both cases the areas under the both peaks are the same, indicating that hydrogen adsorption is completely reversible at the respective catalyst under the given conditions. However, the desoprtion seems to be much faster at $250{ }^{\circ} \mathrm{C}$. The temperature dependence of the calorimetric signals indicates 


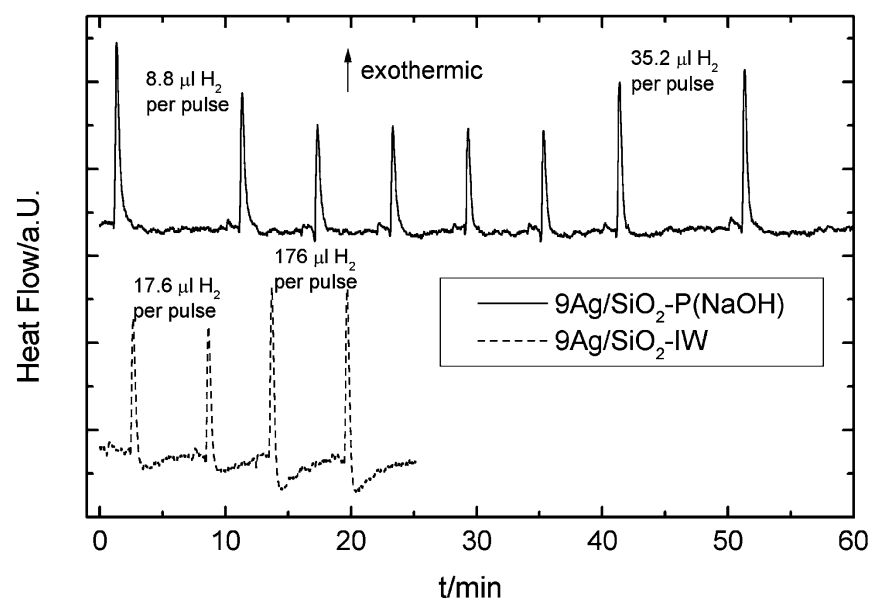

Fig. 6. Comparison of the calorimetric signals caused by hydrogen adsorption at two different silver catalysts at $150{ }^{\circ} \mathrm{C}$. Amount of gas dosed as indicated, $m_{\text {cat }}=100 \mathrm{mg}$ ("IW") and $64 \mathrm{mg}$ ("P").

that the adsorption/desorption of hydrogen at silver is an activated process, consistent with theoretical considerations [11].

Fig. 6 compares the calorimetric response of two different catalysts when exposed to pulses of hydrogen at $150{ }^{\circ} \mathrm{C}$. For the IW catalyst, as described above, the adsorption of hydrogen is completely reversible, i.e. endothermic and exothermic peaks exhibit the same area. For the P-catalyst, at first glance it seems, that no clear endothermic peak can be observed. However, a more detailed examination of the calorimetric signal indicates, that the endothermic signal is very weak and broad. The signal of the thermal conductivity detector indicates, that for the first four pulses, not all the hydrogen is desorbed from the catalyst. However, the amount of hydrogen adsorbed irreversibly at the silver catalysts under the given conditions is very low. Since, due to the slow desorption and the noise in the baseline, it is not possible to determine the amount of exothermic heat irreversibly evolved during hydrogen adsorption with reasonable accuracy, no quantitative analysis of the data is possible at the moment.

\subsection{TAP studies with hydrogen and acrolein}

Interaction of hydrogen as well as acrolein with differently prepared silver catalytic materials has been investigated by single pulse experiments in the TAP reactor using $9 \mathrm{Ag} / \mathrm{SiO}_{2}-\mathrm{IW}$ and $9 \mathrm{Ag} / \mathrm{SiO}_{2}-\mathrm{P}(\mathrm{NaOH})$ catalytic materials as well as electrolytic silver and pure support as reference materials. It was found that hydrogen is consumed in the temperature range from 250 to $400{ }^{\circ} \mathrm{C}$ (see Fig. 7); only ca. $50 \%$ of the pulsed hydrogen desorbed from the catalyst surface at $400{ }^{\circ} \mathrm{C}$ within $1 \mathrm{sec}$. Water was not detected at the reac- 


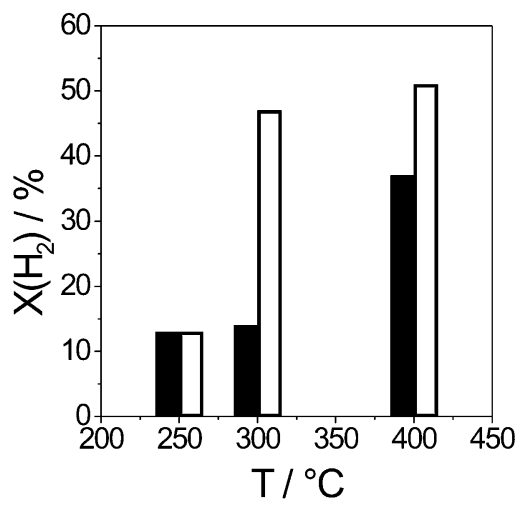

Fig. 7. Conversion of hydrogen during pulsing over $9 \mathrm{Ag} / \mathrm{SiO}_{2}-\mathrm{IW}$ (empty bar) and $9 \mathrm{Ag} / \mathrm{SiO}_{2}-\mathrm{P}(\mathrm{NaOH})$ (black bar) versus temperature.

tor outlet. From the obtained results we can conclude that $9 \mathrm{Ag} / \mathrm{SiO}_{2}-\mathrm{IW}$ and $9 \mathrm{Ag} / \mathrm{SiO}_{2}-\mathrm{P}(\mathrm{NaOH})$ catalytic materials are able to activate gas-phase hydrogen and to stabilise hydrogen species on the catalyst surface. The hydrogen consumption was, however, mostly due to its strong interaction with the catalytic surface coincided with a slow desorption which cannot be monitored within $1 \mathrm{sec}$. In order to prove the existence of surface hydrogen species hydrogen isotopic exchange was also studied at $400{ }^{\circ} \mathrm{C}$. In these experiments, the catalyst has been treated by non-labelled hydrogen, and then deuterium was pulsed over the pretreated catalyst. The products of isotopic exchange such as $\mathrm{H}_{2}$ and $\mathrm{HD}$ were monitored at the reactor outlet. The results obtained reveal the presence of hydrogen species being available on the surface even at high temperature in vacuum. The occurrence of $\mathrm{H} / \mathrm{D}$ exchange can be considered as a test with respect to the dissociative adsorption over $\mathrm{Ag} / \mathrm{SiO}_{2}$ catalytic materials. In this context it is important to mention that no H-D exchange or no measurable interaction of hydrogen with electrolytic silver or pure support material has been found. Fig. 8 presents the normalized transient responses of deuterium and products of hydrogen isotopic exchange during pulsing $\mathrm{D}_{2}$ over two differently prepared $\mathrm{Ag} / \mathrm{SiO}_{2}$ catalytic materials, which were pretreated at $400{ }^{\circ} \mathrm{C}$ by $\mathrm{H}_{2}$ pulsing. As can be seen, the response signal of $\mathrm{D}_{2}$ is very narrow and completed within $<0.2 \mathrm{~s}$ representing the part of the pulsed $\mathrm{D}_{2}$ which does not interact with the catalyst. $\mathrm{HD}$ and $\mathrm{H}_{2}$ were formed as a result of the interaction of gas-phase $\mathrm{D}_{2}$ with surface hydrogen. It is clear that the shape of transient responses of $\mathrm{HD}$ and $\mathrm{H}_{2}$ depends strongly on the materials used (Fig. 8). It is important to note that the ratio of $\mathrm{HD} / \mathrm{H}_{2}$ (both are products of isotopic exchange) is influenced by the catalytic material; $\mathrm{H}_{2}\left(\mathrm{HD} / \mathrm{H}_{2} \sim 0.13\right)$ is the main product of isotopic exchange over $\mathrm{Ag} / \mathrm{SiO}_{2}$ IW, while $\mathrm{HD}\left(\mathrm{HD} / \mathrm{H}_{2} \sim 10.5\right)$ is the main product of isotopic exchange over $\mathrm{Ag} / \mathrm{SiO}_{2}-\mathrm{P}(\mathrm{NaOH})$. Since the transient experiments were carried out in the 

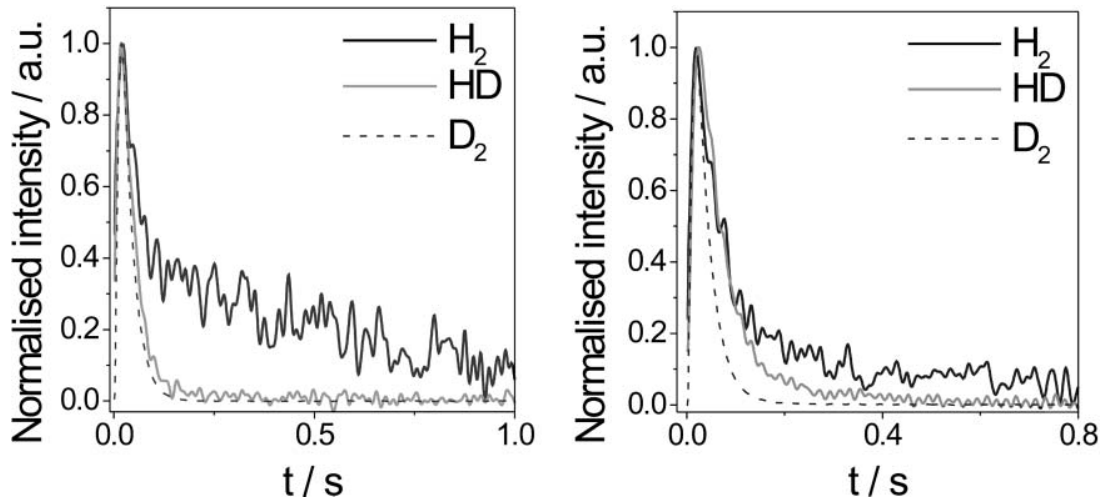

Fig. 8. Normalised transient responses of pulsing $\mathrm{D}_{2}$ over $9 \mathrm{Ag} / \mathrm{SiO}_{2}-\mathrm{IW}$ (left) and $9 \mathrm{Ag} / \mathrm{SiO}_{2}-\mathrm{P}(\mathrm{NaOH})$ (right) at $400{ }^{\circ} \mathrm{C}$. The catalytic materials were pretreated by hydrogen pulsing at $400^{\circ} \mathrm{C}$.

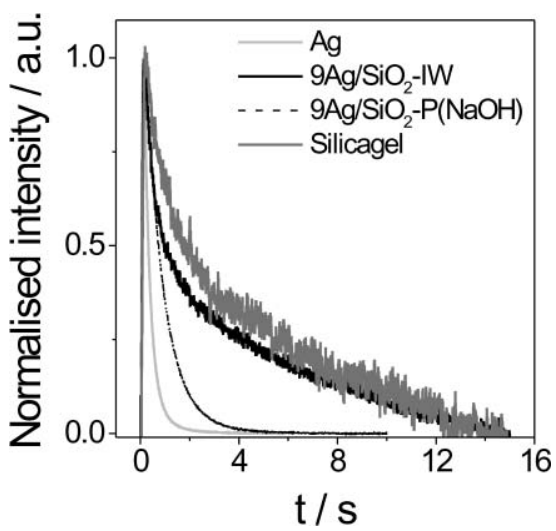

Fig. 9. Transient responses of acrolein pulsing over $\mathrm{SiO}_{2}$, electrolytic silver and $\mathrm{Ag} / \mathrm{SiO}_{2}$ catalytic materials at $250^{\circ} \mathrm{C}$.

Knudsen diffusion regime (no collision between molecules in gas-phase), the differences in the shapes of $\mathrm{HD}$ and $\mathrm{H}_{2}$ transient responses are due to chemical reaction occurring on the catalyst surface. With other words silver at the catalyst surface is responsible for dissociative hydrogen activation. The difference in the ratio of $\mathrm{HD} / \mathrm{H}_{2}$ and in the shapes of transient responses of $\mathrm{HD}$ and $\mathrm{H}_{2}$ for two different $\mathrm{Ag} / \mathrm{SiO}_{2}$ materials indicate that the activation of hydrogen depends on silver distribution, at least under our transient vacuum conditions.

Acrolein adsorption over $\mathrm{Ag} / \mathrm{SiO}_{2}$ catalysts was also studied using the TAP reactor. The normalised transient responses of acrolein are given in Fig. 9. The 
very broad shape of the transient response of acrolein pulsing over pure support material indicates that acrolein interacts strongly with the support and desorbs very slow. Only a weak interaction of acrolein with electrolytic silver was found. As in the case of hydrogen activation differences in catalyst activity for acrolein adsorption were found for $9 \mathrm{Ag} / \mathrm{SiO}_{2}-\mathrm{IW}$ and $9 \mathrm{Ag} / \mathrm{SiO}_{2}$ $\mathrm{P}(\mathrm{NaOH})$ catalytic materials. From Fig. 9 it is clear that the transient response of acrolein pulsing over $9 \mathrm{Ag} / \mathrm{SiO}_{2}-\mathrm{IW}$ is very broad and similar to that over pure silica gel. On the contrary to the above observation, the transient response of acrolein pulsing over $9 \mathrm{Ag} / \mathrm{SiO}_{2}-\mathrm{P}(\mathrm{NaOH})$ is considerably narrow indicating faster acrolein desorption from the catalyst. Based on the shape of acrolein transient responses it may be concluded, that the $9 \mathrm{Ag} / \mathrm{SiO}_{2}-\mathrm{P}(\mathrm{NaOH})$ catalytic material has lower fraction of free surface of the support in comparison to the $9 \mathrm{Ag} / \mathrm{SiO}_{2}-\mathrm{IW}$ material, where additional acrolein adsorption occurs.

Thus the presented results give strong indications that the method of silver deposition onto $\mathrm{SiO}_{2}$ or silver distribution on the catalytic surface influence both hydrogen and acrolein interaction with $\mathrm{Ag} / \mathrm{SiO}_{2}$ catalytic materials.

\subsection{Infrared spectroscopy}

Infrared spectroscopy has been used to study the structure of acrolein adsorbed on silica-supported silver catalyst. Fig. 10 shows IR spectra of acrolein adsorbed a) from $0.5 \mathrm{mbar}$ and b) 5 mbar acrolein in the gas phase at room temperature and c) at $100{ }^{\circ} \mathrm{C}$ as well as d) at $200{ }^{\circ} \mathrm{C}$ in the presence of $\mathrm{H}_{2}$. Various bands can be seen in the $1800-1300 \mathrm{~cm}^{-1}$ region in Fig. 10(a) and (b). The band at 1730 is attributed to physisorbed acrolein, the bands at $1690,1680,1616,1426$ and $1365 \mathrm{~cm}^{-1}$ are assigned to chemisorbed species. All other bands belong to the absorption of gaseous acrolein. For comparison, the adsorption of acrolein has also been studied on silica gel without deposited silver particles. It has been found, that acrolein readily adsorbs on silica gel, exhibiting the same bands as described above. These bands can therefore even in the case of the silver catalyst be assigned to the interaction of acrolein with silanol groups of the support. An interaction of acrolein with silica has already been described in the literature [20,21]. Bands at 1693 and $1684 \mathrm{~cm}^{-1}$ have been found and been assigned to the interaction of the carbonyl group of acrolein via hydrogen bonding with isolated silanol groups and with a pair of vicinal surface silanol groups, respectively [21]. The other bands described above for adsorbed acrolein can be assigned as follows: $1614 \mathrm{~cm}^{-1}(\mathrm{C}=\mathrm{C}$ stretching vibration), $1428 \mathrm{~cm}^{-1}$ (methylene deformation), $1365 \mathrm{~cm}^{-1}$ (CHO deformation). According to spectra recorded at higher temperature and in the presence of hydrogen (Fig. 10(c) and (d)), low amounts of hydrogen-bonded acrolein are present on the surface at $100{ }^{\circ} \mathrm{C}$ and no adsorbed species have been observed at $200{ }^{\circ} \mathrm{C}$. 


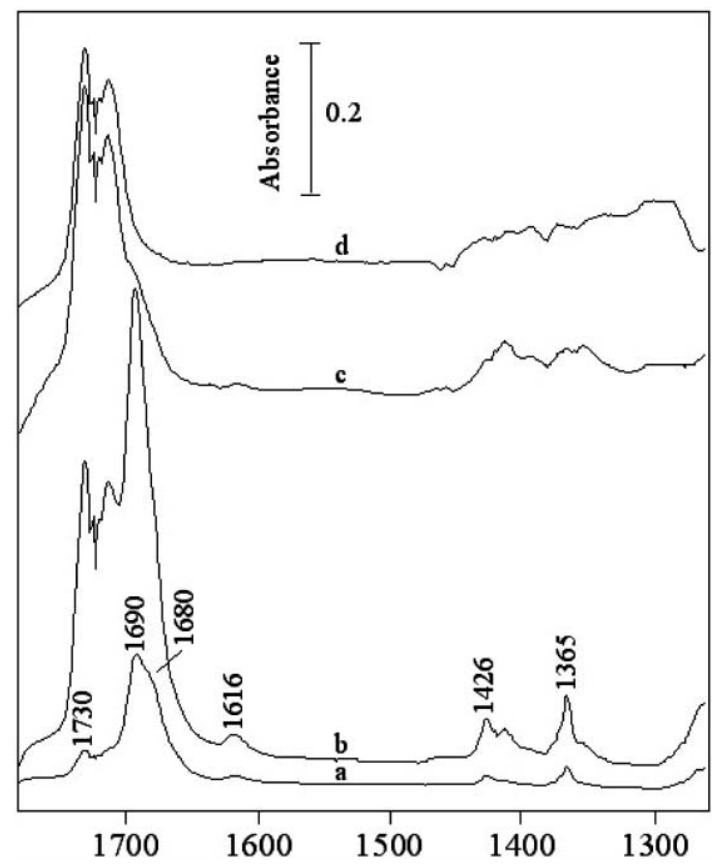

Fig. 10. Infrared spectra of acrolein adsorbed at $40^{\circ} \mathrm{C}$ from a) $0.5 \mathrm{mbar}$ and b) $5 \mathrm{mbar}$ and coadsorption of $15 \mathrm{mbar}$ hydrogen and 5 mbar acrolein at c) $100{ }^{\circ} \mathrm{C}$ and d) $200{ }^{\circ} \mathrm{C}$ on silica supported silver catalyst.

\section{Discussion}

An increasing selectivity towards allyl alcohol with increasing partial pressures of acrolein ( $p_{\mathrm{AC}}=0.1$ to 2 bar) and/or hydrogen $\left(p_{\mathrm{H} 2}=0.2\right.$ to 20 bar $)$ has been observed in the gas phase hydrogenation of acrolein using silver catalysts. This pressure dependence can be observed for different $\mathrm{Ag} / \mathrm{SiO}_{2}$ catalysts, however, the values for the individual selectivities of the various catalysts are different. Taking into account the hypothesis, that the product distribution in the gas phase hydrogenation of silver catalysts is governed by the adsorption structure, it may be suggested, that the dependence of the product distribution on the partial pressure of acrolein is due to a pressure dependent adsorption geometry. Indeed, Itoh and co-workers have found an exposure (i.e., coverage) dependent adsorption geometry of acrolein at evaporated silver films [3]. They propose four types of structures of acrolein at the silver surface at $90 \mathrm{~K}$, with the molecular plane more or less parallel to the surface in all cases. The different structures form successively after increasing exposure to acrolein. Two structures with a direct interaction of acrolein with silver has been found. At higher exposures, multilayer structures are formed. 
The dependence of the selectivities on hydrogen partial pressure is more difficult to understand. Calorimetric measurements indicate, that the hydrogen interaction with silver catalysts is very weak, but exhibits a structure sensitivity. At $150{ }^{\circ} \mathrm{C}$, reversible adsorption with relatively fast desorption has been found over the IW catalyst (small particles), whereas only very slow desorption of hydrogen has been observed over the P-catalyst (larger particles), together with a very small amount of irreversibly adsorbed hydrogen. This means, that on the P-catalyst, surface sites must exist, which are able to stabilise the adsorbed hydrogen. These sites do not exist in the IW catalyst. Additionally, the above TAP results (see Sect. 3.3) have shown, that hydrogen adsorption depends strongly on catalytic materials. Most likely, the different structural properties, i.e. size, edge to plane ratio of the different catalysts are responsible for this behaviour. It may be, that hydrogen activation may only take place at defect sites or kinks, since it is known that no hydrogen dissociation should occur on silver single crystals [10]. Hydrogen atoms may than diffuse into more stable adsorption sites, probably on flat surfaces. Interestingly, the interaction of hydrogen with silver catalyst could be observed at very low pressures (TAP reactor) as well as at ambient pressure (calorimetry). However, all this can not explain the dependence of selectivity on $\mathrm{H}_{2}$ partial pressure. But, since there is, in opposite to the very weak interaction of hydrogen with single crystal silver surfaces, a somewhat stronger interaction of hydrogen with silver nanoparticles, it may be concluded that the hydrogen adsorption including the surface coverage is pressure dependent. This pressure dependent surface coverage influences the catalytic properties of the silver surfaces and leads to a pressure dependent reactivity and selectivity. Also, it is possible that diffusion of hydrogen into the bulk of the silver nanoparticles can, in opposite to the behaviour at single crystals, take place at higher hydrogen pressures, modifying the catalytic properties of the silver [22].

However, as pointed out in part 3.1, the selectivity is not only influenced by the pressure but also by the catalyst preparation method, which most likely means by the size, shape and the surface structure of the catalyst particles. Different preparation methods lead to different particle sizes and size distribution, as can be seen from the TEM result. Mohr et al. have, in a study on supported gold catalysts, concluded, that crystal planes lead to the formation of propanal, whereas edges favour the formation of allyl alcohol [23]. In this context, larger particles, having relatively more atoms on planes than on edges, should favour the formation of propanal. This is consistent with the results obtained in this study, where the catalyst with the smaller particles $\left(9 \mathrm{Ag} / \mathrm{SiO}_{2}\right.$ IW) produced the higher amount of allyl alcohol, whereas the larger silver particles $\left(9 \mathrm{Ag} / \mathrm{SiO}_{2}-\mathrm{P}\right)$ produce lower amounts of allyl alcohol. Indeed, for catalysts with even larger particles, prepared via sputtering of a silver target, the selectivity to allyl alcohol has been found to be even lower than for the $\mathrm{P}$ catalyst ( $\mathrm{ca} .20 \%)$. These results would also be in agreement with results obtained by Fujii et al., which concluded from IR measurements on evapo- 
rated silver films and ab initio-MO-calculations, that electropositive centres like kink sites favour the adsorption of the carbonyl group [3].

Our own IR studies in combination with the TAP results (Fig. 9) indicate that additionally to the interaction of acrolein with silver, also the interaction with the support may have to be taken into account when studying acrolein hydrogenation on disperse $\mathrm{Ag} / \mathrm{SiO}_{2}$ catalysts.

\section{Summary and conclusion}

The hydrogenation of acrolein over differently prepared $\mathrm{Ag} / \mathrm{SiO}_{2}$ catalysts has been studied at various pressures. The selectivities to allyl alcohol and propanal obtained in the hydrogenation experiments is governed by two issues: it depends on the partial pressures of hydrogen and acrolein as well as on the structure of the catalyst. The partial pressure of acrolein most likely influences the adsorption geometry of acrolein, whereas the partial pressure of hydrogen may influence surface coverage by hydrogen species or even solubility of hydrogen into the silver nanoparticles. The structure sensitivity of the selectivities most likely is due to the different ratio of edges to planes in the catalyst.

Additionally, hydrogen activation is an important issue when using silver as hydrogenation catalyst. This hydrogen activation, which may govern the overall activity of the catalysts, is also structure dependent.

\section{Acknowledgement}

The research is funded by the German Research Foundation (DFG, priority program 1091). P.C. thanks the Fonds der Chemischen Industrie for financial support. Experimental help of R. Födisch (TU Chemnitz, group of D. Hönicke) is gratefully acknowledged.

\section{References}

1. P. Claus and H. Hofmeister, J. Phys. Chem. B 103 (1999) 2766.

2. W. Grünert, A. Brückner, H. Hofmeister, and P. Claus, submitted 2004.

3. S. Fujii, N. Osaka, M. Akita, and K. Itoh, J. Phys. Chem. 99 (1995) 6994.

4. J. L. Solomon, R. J. Madix, and J. Stöhr, J. Chem. Phys. 89 (1988) 5316.

5. J. L. Solomon and R. J. Madix, J. Phys. Chem. 91 (1987) 6241.

6. R. N. Carter, A. Brad Anton, and G. Apai, Surf. Sci. 290 (1993) 319.

7. K. R. Christmann, in: Hydrogen Effects in Catalysis, Z. Paál, P. G. Menon, Eds., Marcel Dekker, Inc., New York, Basel, Vol. 31 (1988) p.12.

8. Ph. Avouris, D. Schmeisser, and J. E. Demuth, Phys. Rev. Lett. 48 (1982) 199.

9. J. E. Demuth, D. Schmeisser, and Ph. Avouris, Phys. Rev. Lett. 47 (1981) 1166.

10. V. Zhukov, K. D. Rendulic, and A. Winkler, Vacuum 47 (1996) 5.

11. A. Eichler, G. Kresse, and J. Hafner, Surf. Sci. 397 (1998) 116-136.

12. H. Ehwald, A. A. Shestov, and V. S. Muzykantov, Catal. Lett. 25 (1994) 149. 
13. S. R. Seyedmonir, D. E. Strohmayer, G. J. Guskey, G. L. Geoffroy, and M. A. Vannice, J. Catal. 93 (1985) 288.

14. S. R. Seyedmonir, D. E. Strohmayer, G. L. Geoffroy, M. A. Vannice, H. W. Young, and J. W. Linowski, J. Catal. 87 (1984) 424.

15. M. Bron, A. Knop-Gericke, D. Teschner, A. Scheybal, R. Födisch, D. Hönicke, R. Schlögl, and P. Claus, in preparation.

16. P. Claus, P. A. Crozier, and P. Druska, Fresenius J. Anal. Chem. 361 (1998) 677.

17. M. Lucas and P. Claus, Chem.-Ing.-Techn. 67 (1995) 773.

18. J. T. Gleaves, G. S. Yablonskii, P. Phanawadee, and Y. Schuurman, Appl. Catal. 160 (1997) 55.

19. F. C. Jentoft, J. Kröhnert, M. Bron, R. Schlögl, and P. Claus, unpublished results.

20. G. Y. Popova, A. A. Davydov, T. V. Andrushkevich, and I. I. Zakha, Kinet. Katal. 36 (195) 136.

21. J. E. Bailie, C. H. Rochester, and G. J. Hutchings, J. Chem. Soc. Faraday Trans. 93 (1997) 4389.

22. C. Rehren, M. Muhler, X. Bao, R. Schlögl, and G. Ertl, Z. Phys. Chem. 174 (1991) 11.

23. C. Mohr, H. Hofmeister, J. Radnik, and P. Claus, J. Am. Chem. Soc. 125 (2003) 1905. 